\title{
Type 2 Diabetes and Asthma: Systematic Review of the Bidirectional Relationship
}

\author{
L. Rayner ${ }^{1,2}$, A. McGovern ${ }^{1}$, B. Creagh-Brown ${ }^{1,2}$, C. Woodmansey ${ }^{1,2}$ and S. deLusignan ${ }^{1}$ \\ ${ }^{I}$ Department of Clinical and Experimental Medicine, University of Surrey, Guildford GU2 $7 X H$, UK, ${ }^{2}$ Royal Surrey \\ County Hospital NHS Foundation Trust, Guildford, UK
}

\begin{abstract}
Background and Objective: Obesity is an important contributor to the risk of both asthma and Type 2 Diabetes (T2DM). However, it has been suggested that T2DM and asthma are also independently associated. The aim of this systematic review was to synthesize the evidence for an independent relationship between T2DM and asthma.
\end{abstract}

Methods: MEDLINE and EMBASE were searched for studies reporting the relationship between asthma and T2DM in adults. Given a potential bidirectional relationship, articles relating to T2DM as a risk factor for asthma, and asthma as a risk factor for T2DM were examined separately.

\begin{tabular}{l} 
A R T I C L E H I S T O R Y \\
\hline Received: October 06, 2017 \\
Revised: April 10, 2018 \\
Accepted: July 04, 2018 \\
DOI: \\
10.2174/1573399814666180711114859
\end{tabular}

$10.2174 / 1573399814666180711114859$
Results: Eight studies were identified for inclusion in the review ( $\mathrm{n}=2,934,399$ participants). Four studies examined incident diabetes in those with asthma. The pooled (random effects model) adjusted hazard ratio for incident T2DM in asthma was $1.37(95 \% \mathrm{CI} 1.12-1.69 ; \mathrm{p}<0.001)$ after controlling for BMI.

Four studies reported prevalence or incidence rates of asthma in people with T2DM; higher rates of asthma in those with T2DM were reported in all four studies. Meta-analysis of results was not possible due to methodological heterogeneity.

The quality of included studies was good, but due to small numbers, publication bias cannot be excluded.

Conclusion: The published literature suggests a bidirectional independent relationship between T2DM and asthma, although we cannot exclude publication bias.

Keywords: Type 2 diabetes, asthma, obesity, BMI, incidence.

\section{INTRODUCTION}

For decades, asthma has been viewed as a purely atopic disease. This assertion; although well documented, is now thought to be an oversimplification. More recently, asthma has tentatively been considered as a syndrome, with differences in pathophysiology, onset, co-morbidities and treatment response between patient groups [1,2]. Of the emerging co-morbidities in asthma, obesity is one of the most frequently reported. The odds ratio of asthma in obese individuals compared with those of a normal BMI has been reported as 2.92 (95\% CI 1.39-6.14) in males and 2.67 (95\% CI 1.66-4.29) in females (3] and increasing adiposity is thought to be associated with a dose-dependent increase in the odds of incident asthma [4]. Obesity has also been shown to influence asthma severity; obese patients with asthma experience more frequent exacerbations, a poorer response to treatment and a higher rate of hospitalisation compared to normal-weight asthma patients [5].

*Address correspondence to these authors at the Department of Clinical Medicine and Ageing, University of Surrey, Leggett Building, Daphne Jackson Road, Guildford, GU2 7WG, UK; Tel: +61417292275; E-mails: 1.rayner@surrey.ac.uk; s.lusignan@surrey.ac.uk
A number of large-scale epidemiological studies have provided evidence in favor of a relationship between asthma and Type 2 Diabetes (T2DM), another component of the metabolic syndrome, however, this has not been uniformly replicated [6]. Obesity is a common risk factor for both conditions; the relative risk of T2DM in obese compared with normal weight adults as 4.03 (95\% CI 2.66-6.09) [7]. Furthermore, whilst some studies have looked at asthmainduced chronic inflammation as a risk factor for incident T2DM [8], other works have focused upon T2DM and the associated hyperglycaemia-induced biochemical alterations as the driving force for the development of asthma $[9,10]$, raising the possibility of a bidirectional relationship.

To clarify the association between asthma and T2DM, we conducted a systematic review of the available literature linking the two conditions. In adults with asthma, compared to those without asthma, is there a higher rate of T2DM? Furthermore, given a potential bidirectional relationship, in adults with T2DM, compared to those without T2DM, is there a higher rate of asthma? To our knowledge, this is the first systematic review with the primary objective of analysing the relationship between these conditions. 


\section{MATERIALS AND METHODS}

\subsection{Ethics and Registration}

In accordance with the PRISMA (Preferred Reporting Items for Systematic Reviews and Meta-Analyses) [11] and MOOSE (Meta-analyses of Observational Studies in Epidemiology) [12] guidelines, we registered the objectives, inclusion criteria, search strategies and methods with the International Prospective Register of Systematic Reviews; PROSPERO [13], in May 2017, and published it in the open literature [14]. We ensured all included studies had obtained ethical approval.

\subsection{Search Strategy}

We searched MEDLINE (Ovid) and EMBASE (Ovid) databases for relevant articles published from 2002 up to $10^{\text {th }}$ May 2017. Included studies were limited to those published in the last 15 years. A free-text keyword search was performed using the terms "asthma" and "diabetes", and was restricted to the English language only. We combined searches using the AND Boolean logic operator. We supplemented the database search with a manual search of the reference lists of included studies and previous reviews.

\subsection{Study Selection}

We included studies which were relevant to the scope of the review; because they examined the relationship, directionality or comorbidities of T2DM and asthma. We included all studies which did or did not demonstrate an association between asthma and diabetes. Studies were excluded if they related solely to children (age $<18$ years), type 1 diabetes (T1DM, but mixed samples of T2DM and T1DM were included), or gestational diabetes. Studies examining the effect of medications on the development of T2DM or asthma, those which reported biological markers as the primary outcomes; and reviews, editorials and comments were also excluded. We did not place restrictions on how the index conditions were defined, but considered this in the appraisal process.

Titles and abstracts of records identified in the database search were reviewed independently by two reviewers. Any discrepancies were discussed between the reviewers and were included for full-text searching. Full-texts were then retrieved and also independently reviewed against the inclusion criteria by the two reviewers. Any discrepancies were resolved by discussion with a third independent reviewer. Where the full text was not available, we contacted the corresponding authors.

\subsection{Study Appraisal and Data Analysis}

We grouped the included studies according to the direction in which they examined the asthma-T2DM relationship. We examined each study for study design, population, data collection, adjustment for confounding variables and results. Study quality was assessed using the Newcastle-Ottawa Scale for cross-sectional and cohort studies [15]. Risk of bias was considered and commented upon in the narrative synthesis and appendix.
Based upon the number and methodological similarities between the available studies, we determined whether pooled estimate effects by meta-analysis could be calculated, and presented this in addition to the narrative synthesis of the literature. We assessed each paper for consideration of Body Mass Index (BMI), a potential confounding factor, and used the effect size (hazard ratio or relative risk) calculated after adjustment for BMI as the study outcome where available. Other factors controlled were considered in the narrative synthesis and included smoking status and medications.

Where three or more studies used comparable methods, we performed a meta-analysis using the software package $\mathrm{R}$ (version 3.3.2) and the $\mathrm{R}$ meta-analysis package 'Meta' [16]. We used the DerSimonian and Laird method [17], a noniterative process for estimation of effect size distribution. The assigned weight of each study in the analysis was based on its inverse variance [18]. Where odds ratios were not available these were estimated from reported event rates using the approach described by Tierney et al. [19]. We reported both fixed and random effects pooled estimates with 95\% confidence intervals $(95 \% \mathrm{CI})$. Heterogeneity between studies was quantified using the $\mathrm{I}^{2}$ statistic (with 95\% CI) [20] and $\mathrm{Tau}^{2}$ (also estimated using the DerSimonian and Laird method) with an associated p-value for the likelihood of heterogeneity. Results were displayed using forest plots.

\section{RESULTS}

The flowchart for searches is shown in Fig. (1). We identified 244 articles in our initial search and a further two from scanning reference lists. We removed duplicates leaving 147 titles and abstracts. The main reasons for exclusion at this stage were: the risk of the index conditions not being the primary focus of the study, review or editorial type articles, restriction to children or small subgroups and use of biological markers as reported outcome measures. We subsequently reviewed 31 full-texts, eight of which met the inclusion criteria. Reasons for exclusion are shown in Fig. (1). All included studies had a score of "satisfactory" or above on the Newcastle-Ottawa score [15], with seven studies being rated as "good" or "very good" (see Appendix 1 ). The most common areas of potential bias were recall bias (use of self-report), reporting bias (use of hospital discharge data) and selection bias (male or female only populations).

\subsection{Asthma as a Risk Factor for Type 2 Diabetes}

\subsubsection{Study Characteristics}

The characteristics of the four included studies which evaluated the risk of incident T2DM in people with asthma are displayed in Table 1 [21-24]. These studies included a total of 184,387 participants (range 7,176 [23] to 94,511 [21]) from two countries (USA and Singapore). All four were cohort studies and assessed the risk of incident T2DM in patients with asthma. Two study populations were comprised solely of women, while the other two were mixed populations. All excluded patients with T2DM at baseline and participants were followed up for 5.7-12.2 years. Cases of incident T2DM were detected by self-report in three studies and by database linkage in one. 


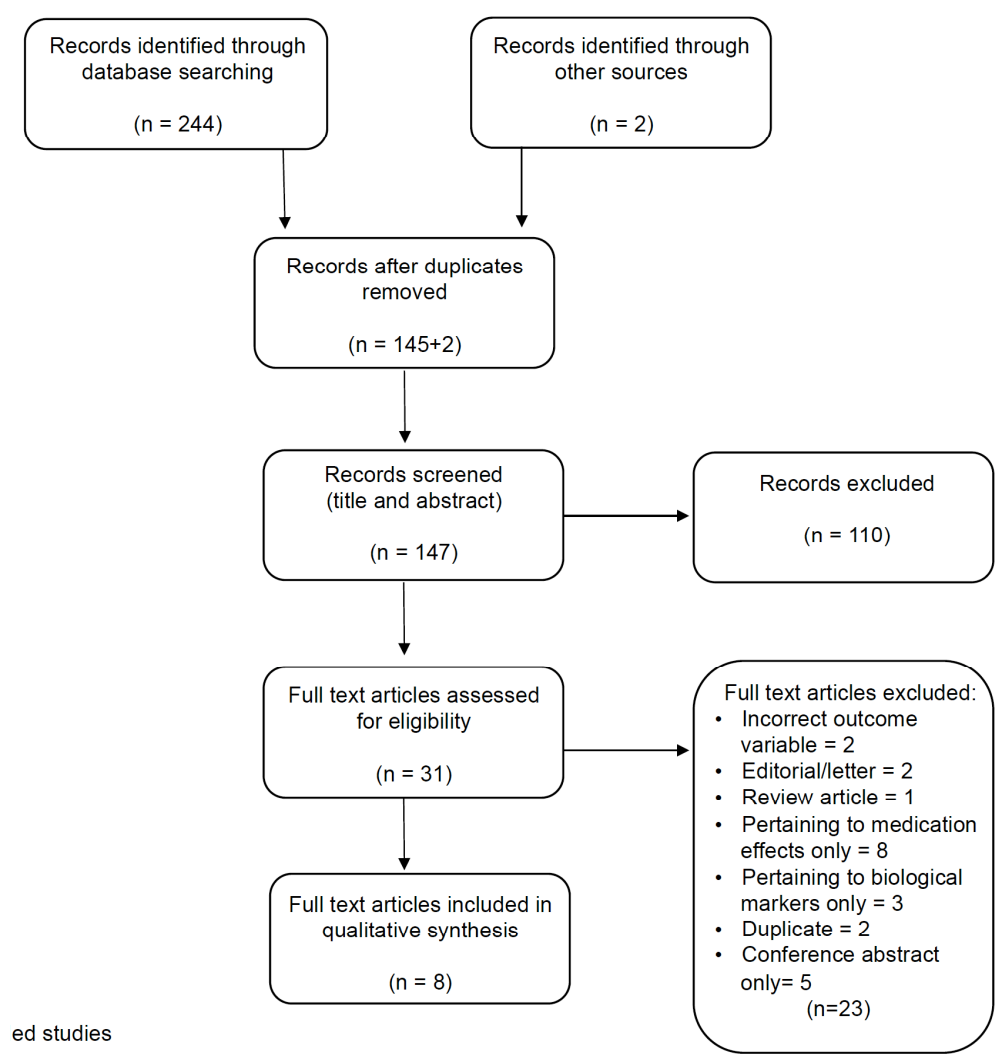

Fig. (1). Flowchart to show included studies.

Table 1. Studies examining the risk of T2DM in people with asthma.

\begin{tabular}{|c|c|c|c|c|c|c|c|}
\hline Author & Study Design & Population & Method of Case Detection & $\begin{array}{l}\text { Separation of } \\
\text { T1 \& T2DM? }\end{array}$ & $\begin{array}{l}\text { Comorbidities Consid- } \\
\text { ered }\end{array}$ & $\begin{array}{l}\text { The result } \\
(95 \% \mathrm{CI})\end{array}$ & $\begin{array}{l}\text { Authors' Conclu- } \\
\text { sions }\end{array}$ \\
\hline $\begin{array}{c}\text { Rana et al., } \\
2004[21]\end{array}$ & $\begin{array}{c}\text { Prospective } \\
\text { cohort } \\
\text { USA }\end{array}$ & $\begin{array}{c}\text { Nurses' Health Study } \\
2879 \text { asthma cases } \\
91632 \text { controls } \\
\text { Age } 30-55 \\
\text { Median follow up } 8 \text { years }\end{array}$ & $\begin{array}{c}\text { Self-reported physician- } \\
\text { diagnosed asthma. } \\
\text { Biannual questionnaire about } \\
\text { incident T2DM-diagnosis or } \\
\text { insulin/oral anti-diabetic } \\
\text { prescription }\end{array}$ & $\begin{array}{c}\text { Yes } \\
\text { T2DM only }\end{array}$ & $\begin{array}{c}\text { Accounted for BMI, } \\
\text { smoking, family history } \\
\text { of diabetes. } \\
\text { No data on asthma } \\
\text { severity. Prevalence of } \\
\text { oral steroid documented. }\end{array}$ & $\begin{array}{l}\text { RR } 1.0 \\
(0.8-1.2)\end{array}$ & $\begin{array}{l}\text { No relationship } \\
\text { between asthma and } \\
\text { T2DM risk, but } \\
\text { relationship was } \\
\text { seen between COPD } \\
\text { and incident T2DM }\end{array}$ \\
\hline $\begin{array}{l}\text { Song et al., } \\
2010[22]\end{array}$ & $\begin{array}{l}\text { Prospective } \\
\text { cohort } \\
\text { USA }\end{array}$ & $\begin{array}{c}\text { Women's' Health Study } \\
3368 \text { patients with asthma } \\
32248 \text { controls } \\
\text { Age }>=45 \\
\text { Median follow up } 12.2 \text { years }\end{array}$ & $\begin{array}{c}\text { Self-report of physician- } \\
\text { diagnosed asthma at baseline } \\
\text { Annual questionnaire about } \\
\text { incident T2DM (verified with } \\
\text { follow up questionnaire) }\end{array}$ & $\begin{array}{c}\text { Yes } \\
\text { T2DM only }\end{array}$ & $\begin{array}{l}\text { Accounted for BMI and } \\
\text { smoking. } \\
\text { No data on medications } \\
\text { or asthma severity. }\end{array}$ & $\begin{array}{l}\text { RR } 1.7 \text { (1.5-1.93) } \\
\text { After adjusting for } \\
\text { BMI RR 1.37, } \\
\quad(1.2-1.57)\end{array}$ & $\begin{array}{l}\text { Asthma associated } \\
\text { with an increased } \\
\text { risk of incident } \\
\text { T2DM in women }\end{array}$ \\
\hline $\begin{array}{l}\text { Yun et al., } \\
2012[23]\end{array}$ & $\begin{array}{c}\text { Retrospective } \\
\text { cohort } \\
\text { USA }\end{array}$ & $\begin{array}{l}2392 \text { asthmatic patients and } \\
4784 \text { controls. } \\
57 \% \text { male } \\
44 \% \text { of patients under } 18 \text { at } \\
\text { end of the study period } \\
\text { Median follow up } 7 \text { years } \\
\text { asthmatic and } 5.8 \text { years non- } \\
\text { asthmatic patients }\end{array}$ & $\begin{array}{l}\text { A search of large healthcare } \\
\text { database with records from } \\
\text { primary and secondary care. } \\
\text { Note study period } 1964-1983\end{array}$ & No & $\begin{array}{c}\text { Did not account for BMI } \\
\text { and smoking. } \\
\text { No data on medications } \\
\text { or asthma severity. }\end{array}$ & $\begin{array}{c}\text { HR } 2.11 \\
(1.43-3.13)\end{array}$ & $\begin{array}{l}\text { Asthma increased } \\
\text { the risk of incident } \\
\text { diabetes }\end{array}$ \\
\hline $\begin{array}{c}\text { Mueller } \text { et } \\
\text { al., } 2013 \\
{[24]}\end{array}$ & $\begin{array}{l}\text { Prospective } \\
\text { cohort } \\
\text { Singapore }\end{array}$ & $\begin{array}{c}5115 \text { cases of asthma } \\
41969 \text { controls } \\
\text { Age } 45-74 \\
\text { Mean age } 46.5 \\
\text { Median follow up } 5.7 \text { years }\end{array}$ & $\begin{array}{c}\text { Self-reported physician- } \\
\text { diagnosed asthma at baseline } \\
\text { Incident DM classified if } \\
\text { developed anytime between } \\
\text { enrolment and the follow-up } \\
\text { an interview at the end of the } \\
\text { study }\end{array}$ & $\begin{array}{c}\text { Yes } \\
\text { T2DM only }\end{array}$ & $\begin{array}{c}\text { Accounted for BMI, } \\
\text { smoking, passive } \\
\text { smoking. } \\
\text { No data on medications } \\
\text { or asthma severity }\end{array}$ & $\begin{array}{c}\text { HR 1.31 } \\
(1.00-1.72) . \\
\text { After adjusting for } \\
\text { BMI HR 1.25 } \\
(0.95-1.64) \\
\text { In the group with } \\
\text { BMI }>27.5 \\
\text { HR } 1.95 \\
(1.12-3.41)\end{array}$ & $\begin{array}{l}\text { Positive association } \\
\text { between asthma } \\
\text { T2DM risk, attenu- } \\
\text { ated by adjustment } \\
\text { for BMI. } \\
\text { Association reached } \\
\text { significance in BMI } \\
>27.5 \text { subgroup }\end{array}$ \\
\hline
\end{tabular}




\subsection{Association Between Asthma and Incident T2DM}

\subsubsection{Narrative Synthesis}

Two included studies reported a significantly higher risk of T2DM in participants with asthma (RR 1.37, 95\% CI 1.21.57 and HR 2.11, 95\% CI 1.43-3.14) [22, 23]. Song et al. examined a prospective cohort of female health professionals followed up over 12.2 years [22]. Participants with preexisting asthma had a higher risk of developing T2DM compared with a control group, after adjustment for BMI, smoking and family history of diabetes (RR 1.37, 95\% CI 1.21.57). Prior to adjustment for BMI, the RR was 1.70 (1.51.93). Diagnoses of asthma and incident T2DM were ascertained by self-report of a physician diagnosis. A subset of those who reported a T2DM diagnosis were then validated using physician-led telephone interviews, with a positive predictive value of $>91 \%$. In a retrospective cohort study by Yun et al. [23], 2,392 people with asthma and 4,784 nonasthmatic controls were compared for their risk of incident pro-inflammatory conditions: Inflammatory Bowel Disease (IBD), Rheumatoid Arthritis (RA), Coronary Artery Disease (CAD) and diabetes (type 1 or type 2). The asthma cohort was identified using predetermined diagnostic criteria and cases of diabetes were obtained from electronic healthcare database codes. The majority of the patients had childhooddiagnosed asthma (mean age of diagnosis 15 years, median age 5 years). Over a median follow-up period of seven years for the asthma group and 5.8 years for controls, asthma status was associated with an increased risk of incident diabetes (HR 2.11, 95\% CI 1.43-3.14). Importantly, this was not adjusted for BMI, and cases of T1DM and T2DM were not distinguished. Forty-four percent of patients were still under 18 at the end of follow up.

After adjustment for BMI, two included studies did not observe a significant relationship between asthma and T2DM (RR 1.0, 95\% CI 0.8-1.2 [20] and HR 1.25, 95\% CI 0.95-1.64 [24]). Rana et al. [21] observed no difference in T2DM risk between 2879 participants with asthma and 91632 participants without over an 8 year follow-up period (RR 1.0, 95\% CI 0.8-1.2). T2DM cases were identified by the participant-reported fulfillment of the known international diagnostic criteria or the prescription of insulin or antidiabetic therapy. BMI was adjusted for. A cohort of patients with Chronic Obstructive Pulmonary Disease (COPD) was also identified, and an increased incidence of T2DM was seen in that group compared to controls RR 1.8 (1.1-2.0). Mueller et al. [24] observed a significant association between self-reported physician-diagnosed asthma and incident
T2DM over a 5.7 year follow-up period in the Singapore Chinese Health Study. After adjustment for BMI, this finding did not reach significance (HR 1.25 95\% CI 0.95-1.64). The asthma-diabetes association was stronger for adult versus childhood-onset asthma (HR 1.62 [95\% CI 1.03-2.55] and HR 1.12 [95\% CI 0.65-1.93] respectively), and for overweight- versus non-overweight patients (HR 1.69 [95\%CI 1.05-2.73] vs. HR 1.10 [95\% CI 0.79-1.53]).

\subsubsection{Meta-analysis}

The four included studies were of sufficiently similar study design to allow the calculation of pooled effect size by meta-analysis. In the pooled sample there was a significant trend towards a greater risk of incident diabetes in those with asthma in both the fixed effect model HR 1.34 (95\%CI 1.19$1.53 ; \mathrm{p}<0.001)$ and random effects model HR $1.37(95 \% \mathrm{CI}$ $1.12-1.69 ; \mathrm{p}=0.001)$. There were too few studies to reliable estimate heterogeneity $\left(\mathrm{Tau}^{2}=0.147 \% ; \quad \mathrm{I}^{2}=58.8 \% \quad[95 \% \mathrm{CI}\right.$ $0.0-86.3 \%]$ ) although it appears that there was a reasonable agreement between the studies (see Fig. 2).

We intended to check for asymmetry in the distribution of effect sizes using funnel plots, where studies were pooled, to assess the possibility of publication bias. However, there was an insufficient number of studies to warrant this analysis [25].

\subsection{Type 2 Diabetes as a Risk Factor for Asthma}

\subsubsection{Study Characteristics}

The characteristics of the four included studies which evaluated the risk of incident asthma in people with T2DM are displayed in Table 2 [10, 26-28]. The studies included a total of 2,750,012 participants (range 34,728 [27] to $1,811,228$ [10]) from three countries (USA, Taiwan and Denmark). Two were cross-sectional studies and two were retrospective cohorts. Two examined the incidence of asthma in patients with T2DM, and two assessed the prevalence. The cohort studies excluded patients with asthma at baseline. Three studies used data from the large health record databases and one used survey responses from a large twin study. Two studies accounted for BMI, one adjusted for 'obesity' but not specifically BMI, and one did not adjust for weight at all.

Pooled effect estimates were not calculated due to significant selection and methodological differences between the studies.

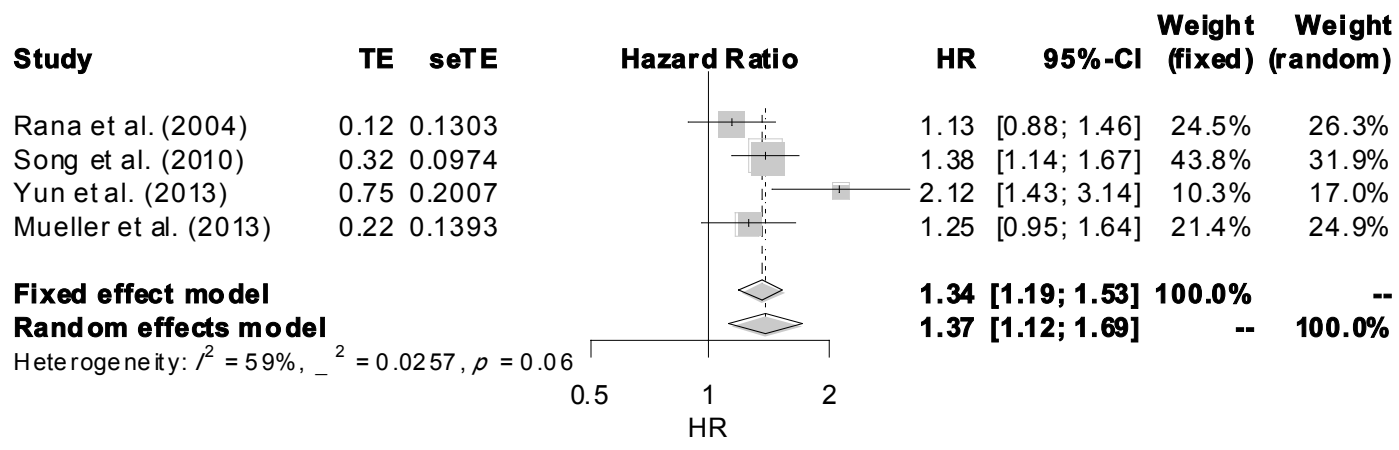

Fig. (2). Forrest plot of meta-analysis. 
Table 2. Studies examining the risk of asthma in people with T2DM.

\begin{tabular}{|c|c|c|c|c|c|c|c|}
\hline Author & Study Design & Population & $\begin{array}{c}\text { Method of Case } \\
\text { Detection }\end{array}$ & $\begin{array}{l}\text { Separation of } \\
\text { T1 \& T2DM? }\end{array}$ & $\begin{array}{l}\text { Comorbidities } \\
\text { Considered }\end{array}$ & $\begin{array}{c}\text { Result } \\
(95 \% \mathrm{CI})\end{array}$ & Authors' Conclusions \\
\hline $\begin{array}{c}\text { Hashemzadeh et } \\
\text { al., } 2009 \\
{[26]}\end{array}$ & $\begin{array}{c}\text { Cross-sectional } \\
\text { USA }\end{array}$ & $\begin{array}{c}\text { Hospital inpatients } \\
293124 \text { with T2DM } \\
552624 \text { controls } \\
97 \% \text { males. } \\
\text { Mean age } 65 \\
\text { Control group with HTN }\end{array}$ & Hospital discharge data & $\begin{array}{c}\text { Yes } \\
\text { T2DM only }\end{array}$ & $\begin{array}{l}\text { Did not adjust for } \\
\text { BMI } \\
\text { No data on medica- } \\
\text { tions }\end{array}$ & $\begin{array}{c}\text { OR } 2.99 \\
(2.92-3.06)\end{array}$ & $\begin{array}{l}\text { Prevalence of asthma signifi- } \\
\text { cantly higher in hospitalised } \\
\text { patients with T2DM than in } \\
\text { controls }\end{array}$ \\
\hline $\begin{array}{c}\text { Ehrlich et al., } \\
2010 \\
{[10]}\end{array}$ & $\begin{array}{c}\text { Retrospective } \\
\text { cohort } \\
\text { USA }\end{array}$ & $\begin{array}{c}\text { Health records } \\
77637 \text { participants with DM } \\
1733591 \text { controls } 53.4 \% \text { male } \\
\text { Median age } 51 \\
\text { Follow up 6 years }\end{array}$ & $\begin{array}{c}\text { Asthma cases identi- } \\
\text { fied by hospital } \\
\text { discharge } \\
\text { DM cases detected } \\
\text { using diabetes registry }\end{array}$ & No & $\begin{array}{c}\text { Adjusted for } \\
\text { smoking and BMI. } \\
\text { No data on medica- } \\
\text { tions }\end{array}$ & $\begin{array}{c}\text { HR } 1.08 \\
(1.03-1.12)\end{array}$ & $\begin{array}{l}\text { Individuals with DM were at } \\
\text { an increased risk of asthma. } \\
\text { No relationship between } \\
\text { HbAlc and incidence of } \\
\text { asthma }\end{array}$ \\
\hline $\begin{array}{c}\text { Thomsen et al., } \\
2011 \\
{[27]}\end{array}$ & $\begin{array}{c}\text { Cross-sectional } \\
\text { twin study } \\
\text { Denmark }\end{array}$ & $\begin{array}{c}\text { Twin database } \\
459 \text { with T2DM. } \\
34293 \text { controls` } \\
46 \% \text { of males } \\
\text { Median age bracket } 41-50\end{array}$ & $\begin{array}{c}\text { Self-reported asthma } \\
\text { diagnosis by question- } \\
\text { naire. } \\
\text { DM cases detected } \\
\text { using diabetes registry }\end{array}$ & $\begin{array}{c}\text { Yes } \\
\text { T2DM only }\end{array}$ & $\begin{array}{l}\text { Controlled for BMI, } \\
\text { smoking, and } \\
\text { COPD. } \\
\text { No data on medica- } \\
\text { tions }\end{array}$ & $\begin{array}{c}\text { Men OR } \\
1.70 \\
(1.07-2.7) \\
\text { Women OR } \\
1.88(1.24- \\
2.85)\end{array}$ & $\begin{array}{l}\text { Prevalence of asthma was } \\
\text { almost doubled in twin with } \\
\text { T2DM compared with non- } \\
\text { diabetic twin }\end{array}$ \\
\hline $\begin{array}{c}\text { Chen et al., } 2017 \\
{[28]}\end{array}$ & $\begin{array}{c}\text { Retrospective } \\
\text { cohort } \\
\text { Taiwan }\end{array}$ & $\begin{array}{c}19428 \text { patients with diabetes } \\
\text { and } 38856 \text { matched controls } \\
49 \% \text { of males } \\
\text { Mean age } 62\end{array}$ & Medical claims data & $\begin{array}{c}\text { No } \\
\text { Note however } \\
84.7 \% \text { of the } \\
\text { DM patients } \\
\text { were not on } \\
\text { insulin }\end{array}$ & $\begin{array}{c}\text { Accounted for } \\
\text { obesity (not BMI) } \\
\text { Data on insulin and } \\
\text { antidiabetic medica- } \\
\text { tions }\end{array}$ & $\begin{array}{c}\text { HR } 1.30 \\
(1.24-1.38)\end{array}$ & $\begin{array}{l}\text { Risk of incident asthma } \\
\text { higher in patients with diabe- } \\
\text { tes. } \\
\text { (Insulin use may increase the } \\
\text { risk of developing asthma, } \\
\text { metformin use may reduce the } \\
\text { risk of developing asthma) }\end{array}$ \\
\hline
\end{tabular}

\subsubsection{Association Between T2DM and Asthma}

\subsection{Narrative Synthesis}

All four studies included reported higher rates of asthma in participants with diabetes. Two studies reported an increased prevalence of asthma in participants with T2DM $[26,27]$, and two reported an increased incidence of asthma in participants with diabetes $[10,28]$. Of the prevalence studies, Hashemzadeh et al. [26], used hospital discharge data to compare the prevalence of asthma in 293,124 hospital inpatients with T2DM and 552,624 non-matched controls with hypertension. Asthma was present in $4.5 \%$ of patients with T2DM compared with $2.9 \%$ of controls. After adjustment for comorbidities, T2DM remained independently associated with asthma (OR 2.99, 95\% CI 1.92-3.06). Notably, the study was conducted in a population comprising of $97 \%$ males. Furthermore, only hospital discharge data were used, and BMI was not accounted for. No data were obtained regarding the duration of diabetes and asthma diagnoses and hence no means of assessing the temporality or direction of the relationship. A Danish study of 34,782 twins [27] showed that the prevalence of asthma was significantly higher in people with T2DM compared to controls in both males $(13.5 \%$ vs. $7.5 \%)$ and in females $(16.6 \%$ vs. 9.6\%), after adjustment for BMI and smoking. Significant genetic correlations were found between asthma and T2DM in all subjects $(0.20,95 \%$ CI $0.01-0.40)$, and between asthma and BMI in women $(0.15,95 \%$ CI $0.07-0.22)$.
Both incidence studies did not specifically exclude patients with T1DM, however the median age of participants in these studies was 51 years [10] and 62 years [28], and $84.7 \%$ of participants in the study by Chen et al. were not prescribed with insulin [28]. Ehrlich et al. conducted a large retrospective cohort study of Californian patients using health care plan data [10]. The cohort consisted of 77,637 participants with diabetes (T1DM and T2DM) and 1,733,591 adult controls, with data on potential confounders available for a subset. The incidence of asthma was significantly higher in the group with diabetes than in the control group, and remained so after adjustment for age, smoking and BMI (HR 1.08, 95\% CI 1.03-1.12). There was no relationship between glycated hemoglobin and the incidence of asthma in people with diabetes. Like Hashemzadeh et al. [26], the authors used primary hospital discharge diagnoses of "asthma" for case detection.

The most recent study investigating the incidence of asthma in patients with diabetes was conducted by Chen et al. [28] using medical claims data in Taiwan. A retrospective cohort, conducted between 2000 and 2010, demonstrated an increased risk of asthma in individuals with diabetes as compared to matched controls (13.5 versus 10.3 per 1000 respectively). Results were adjusted for obesity, but not specifically for BMI. In contrast to other studies, data relating to antidiabetic medications were collected. Participants with diabetes who received more than three prescriptions for insulin in a given year were significantly more likely to develop 
asthma than participants with diabetes who did not use insulin (OR 2.23, 95\% CI 1.52-3.58). Meglitinides were also shown to demonstrate this effect. Conversely, the risk of asthma decreased $25 \%$ in people with diabetes who took metformin compared with those who did not.

\section{DISCUSSION}

Our systematic review and meta-analysis find an overall greater risk of incident T2DM in individuals with asthma, after attempts to control for BMI. We also observed a higher prevalence and risk of incident asthma in people with T2DM, suggesting that the asthma-T2DM relationship may be bidirectional, although this relationship could not be quantified by meta-analysis due to study heterogeneity. Consideration is also given to residual confounding factors for the observed findings. This is the first systematic review of epidemiological studies on the interaction between these two conditions.

\subsection{Asthma as a Risk Factor for Incident T2DM: Puta- tive Mechanisms}

\subsubsection{Pro-inflammatory Cytokines}

Chronic inflammation was referred to in all of the studies investigating asthma as a risk factor for the development of T2DM. Asthma is associated with the upregulation of a myriad of pro-inflammatory cytokines; TNF $\alpha$, IL-6, IL-8 and adhesion molecules, likely through its activation of nuclear factor-kB [24]. Elevated levels of these cytokines have been shown to be associated with an increased risk of T2DM [28]. It has been suggested that chronically elevated levels of these cytokines in asthma may lead to the development of insulin resistance and eventual T2DM. However, the cytokine response in asthma is mainly localized to the airways, and hence the mechanism by which isolated airways inflammation may lead to insulin resistance remains unclear.

Notably, data discussed in this review from a large American cohort of nurses [21] did not demonstrate an increased risk of T2DM in the asthma group but did in COPD patients. The authors suggested that this may be due to the differences in the cellular infiltrates associated with asthma and COPD, with a Th2 helper cell predominance in asthma compared with a Th1 predominance in COPD. This proposition was declined by Song et al., who conducted a similar study in American women, [22] stating that this has not been supported by other experimental or observational data, and proposed that differences in lifestyle variables and length of follow-up could explain the differences between their study and that of the nursing cohort (21]. There do not appear to be any critical differences in baseline characteristics between the populations involved in the two studies in question, with both accounting for similar confounding variables (BMI and smoking), and both separating out COPD patients. Yun et al. [23] also referred to pro-inflammatory cytokines in their study investigating incident diabetes in asthma. Cases of T1 and T2DM were not distinguished, and hence more than one mechanism may be responsible for their observations.

\subsubsection{Intermittent Hypoxia}

Intermittent hypoxia, has been shown to be associated with the phenotype of obese adult asthma [30], has also been suggested to worsen glucose control [31]. This fits with two studies included in this review $[22,24]$ in which the asthmaT2DM link was not significant in those with a normal BMI, but was in the overweight or obese groups. Importantly, hypoxia in obese asthma may be mediated by Obstructive Sleep Apnoea (OSA), and pure asthma in the absence of OSA would be highly unlikely to induce hypoxia.

\subsubsection{Confounding Factors}

A key confounding factor which was not accounted for in any of the included studies was the prescription of oral steroids. A short course of prednisolone is often prescribed during acute exacerbations of asthma, and regular oral prednisolone is occasionally prescribed in severe asthma, refractory to inhaled treatments. The prevalence of steroid-induced diabetes in patients with respiratory illness has been reported to be as high as $14.7 \%$ [32]. Oral steroids could therefore have a significant impact upon the T2DM risk in asthma patients. There are mixed data relating to the effect of inhaled corticosteroids, which are prescribed for the vast majority of patients with asthma on diabetes incidence, although they may worsen glycaemic control in those with established diabetes [33]. Inhaled corticosteroid prescription was not assessed in any of the included studies.

\subsection{T2DM as a Risk Factor for Incident Asthma: Puta- tive Mechanisms}

\subsubsection{Microvascular Damage - the "Diabetic Lung"}

In addition to asthma as a risk factor for T2DM, this review also found higher rates of asthma in people with T2DM. This adds to emerging evidence which suggests that the lung may be a target organ for diabetic microangiopathy. Many diabetic complications result from capillary damage, yet despite having a very large capillary network, pulmonary complications of diabetes are rarely reported. Changes in the lung are likely to remain subclinical due to the great microvascular reserve in the alveolar-capillary network [34].

Microvascular damage as a result of diabetes has been demonstrated by assessment of the diffusion capacity for carbon monoxide (DLCO), which is influenced by alveolarcapillary membrane thickness and pulmonary blood flow. The general consensus from numerous studies in patients with both T1 and T2DM demonstrate a reduced DLCO in comparison with controls, in a manner which correlates with the severity of other microvascular complications [34, 35). Histopathologically, a thickened alveolar-capillary membrane has been demonstrated in individuals with diabetes suggesting that, as in retinopathy and nephropathy, increased vessel wall thickness is the pathological hallmark [34).

\subsubsection{Functional Lung Effects}

A meta-analysis of 40 studies evaluating pulmonary function in participants with diabetes-free from overt pulmonary disease reported a modest but significant reduction in FEV1 and FVC, in a restrictive lung disease pattern [36]. These findings are therefore not uniformly consistent with the obstructive deficit characteristic of asthma, making it difficult to attribute incident asthma wholly to diabetic mi- 
croangiopathy of the lung. Nonetheless, restrictive spirometry is seen in patients with asthma who are obese [37], older and female [38], and thus asthma induced by the "diabetic lung" may manifest in a similar way to this. Poorer control of bronchial smooth muscle tone (potentially due to autonomic neuropathy) [34, 39] has been reported, and decrements in lung function have also been seen in patients with impaired fasting glucose [40], a subset of "pre-diabetes". Changes seen in "the diabetic lung" are likely to be subclinical in the majority but may become clinically important in patients with comorbid lung conditions [34] or pulmonary disease risk factors. In these patients, T2DM may lead to the unmasking of respiratory symptoms or worsening of control.

\subsubsection{T2DM Treatments}

The study by Chen et al. [28], which found a higher incidence of T2DM in those treated with insulin or meglitinides and a lower rate in those taking metformin, raises the interesting possibility that the incidence of asthma may be influenced by T2DM treatments. The lung is known to have insulin receptors, and high levels of insulin binding may promote airway smooth muscle contraction and hyper-responsiveness [41]. Meglitinides increase the release of insulin from beta cells. A higher asthma incidence in patients prescribed meglitinides adds further backing to the proposal that hyperinsulinemia plays a role in the observed asthmadiabetes relationship [42]. Moreover, whilst the insulinasthma relationship could have been confounded by a high number of patients with T1DM being represented in the insulin group, this would not be the case with meglitinides, which are solely used for T2DM.

Metformin has been shown to reduce the risk of incident asthma [28]. Metformin is known to be a pharmacological adenosine monophosphate-activated protein kinase (AMPK) activator [43]. AMPK plays a role in reducing airway inflammation and has anti-oxidative and anti-tissue remodeling properties [44]. Consequently, metformin may have a role in the control of asthma in patients with elements of the metabolic syndrome, and this may be a target for further research.

\subsubsection{Confounding Factors}

Although all four included studies reported an increased risk of asthma in patients with diabetes, two studies did not separate cases of T1 and T2DM [10, 28]. We are therefore unable to solely attribute our findings to T2DM and have to consider the effect T1DM may have on asthma risk. Previous work has found a positive association between T1DM and asthma onset, suggesting a shared susceptibility to both conditions [45]. A positive relationship between T1DM and incident asthma may be due to the effect of insulin as discussed above [41, 42].

Other residual confounders which may have had an impact upon results include smoking, which was not controlled for in two studies $[26,28]$ as it is a known risk factor for T2DM [46] and precipitant of obstructive airways disease.

\subsection{Is there a Bidirectional Relationship Between T2DM and Asthma?}

A significant trend towards incident diabetes in individuals with asthma was demonstrated by meta-analysis in this review. All four of the examined studies referred to the chronic inflammatory state and cytokine over-expression induced by asthma as the potential driving force for the development of diabetes

However, in light of the evidence reviewed, it is likely that this is not a unidirectional relationship. A higher prevalence and incidence of asthma in people with T2DM was also observed. This may be due in part to diabetic complications in the lung at a microvascular level, however, it is not clear how this translates into obstructive lung function and airway hyper-responsiveness. These findings lead us towards a likely bidirectional relationship.

\subsection{No Independent Relationship?}

Despite the meta-analysis favoring asthma as a risk factor for T2DM, two studies did not demonstrate this after controlling for BMI [21, 24], and the risk of T2DM was highest in obese asthmatics [24]. Obesity plays a significant role in each of the arguments discussed. Obesity may increase T2DM risk in the same ways that we propose asthma can: through a low-grade inflammatory state and the stress of intermittent hypoxia. Obesity may increase the risk of asthma in similar ways to those we have attributed to T2DM: adverse effects on chest mechanics and via increased insulin resistance, requiring increased insulin doses and subsequent bronchoconstriction. Obesity could therefore, represent more than a confounding variable but a key component of a more complex metabolic relationship involving three conditions.

\subsection{Limitations of the Available Evidence}

This review used a comprehensive methodology following PRISMA [11] and MOOSE [12] guidelines, in which all included studies met satisfactory quality requirements [15] and represent data from nearly three million participants.

Only eight studies met the inclusion criteria; four for each arm of the bidirectional relationship. The high level of heterogeneity between the four T2DM $\rightarrow$ asthma studies precluded calculation of an overall effect size as two were cross-sectional (prevalence of asthma) and two were retrospective cohorts (incidence of asthma). Whilst studies were of sufficient methodological similarity for pooling in asthma $\rightarrow$ T2DM relationship, we were unable to evaluate asymmetry in the distribution of effect sizes using funnel plots to assess the possibility of publication bias due to an insufficient number of studies. Observational studies are at high risk of publication bias, especially those which report associations between a number of different conditions (as seen in Rana et al. [21] and Yun et al. [23]), and hence represents an important consideration here. Despite methodological similarities, the studies included in the meta-analysis were from different populations. Two were female-only populations and one had a significant proportion of under $18 \mathrm{~s}$, which could influence the generalisability of the results.

Methods of index condition detection were not uniformly robust. None reached the top standards for case detection as per the Newcastle-Ottawa scores [15], with many using databases or self-report. Self-report of respiratory conditions 
can lead to the misclassification of asthma as COPD [27], which could represent a source of bias. Furthermore, three studies used hospital record data alone, potentially only accounting for more severe cases of the index conditions. Additionally, whilst studies concerning only T1DM were excluded from the review, those with mixed diabetic populations were permitted (three of the eight included), reducing the ability to attribute the effect seen solely to T2DM and not to diabetes in general.

\section{RESEARCH IMPLICATIONS}

The limitations of the currently available evidence highlight the need for a large well-designed trial to investigate the asthma-diabetes relationship further. Clear strategies for the identification of index conditions (avoiding reliance upon self-report) and control of important confounders such as BMI and oral steroid use is required to conclusively determine if there is an independent association between asthma and diabetes.

\section{CLINICAL IMPLICATIONS}

Prevention of T2DM in high-risk individuals through weight loss and increased physical activity is well documented [47]. Smoking cessation, control of hypertension and reducing health inequalities are also important factors [48]. Prevention of asthma in high-risk individuals is less clearcut, as although numerous associations have been made, substantiation of causality has yet to be determined. Reducing obesity (particularly childhood obesity), tobacco exposure avoidance and breastfeeding have all been shown to be one's lifetime risk of asthma, and these are the areas prevention strategies could focus upon [49].

The sum of the literature presented herein demonstrates a high rate of comorbid asthma and T2DM and suggests plausible contributory mechanisms for this. If T2DM is a risk factor for incident asthma, this highlights the importance of modulating the common factor, obesity, to reduce this risk. Overweight and obese patients with both conditions should be made aware that losing weight could improve both their asthma and diabetic control, and helping them to do this could form a key component of their care.

Suggestions have also been made as to the influence of medications used in diabetes (metformin, meglitinides and insulin) on asthma control. Awareness of the potential cooccurrence of the two conditions could therefore influence the optimal prescribing choices. Regarding the bidirectional relationship, the potential for diabetes to be a key modulator in asthma pathogenesis adds further weight to ongoing work regarding the different phenotypes of asthma, which may each benefit from different management.

\section{CONCLUSION}

Our systematic review and meta-analysis find a greater risk of T2DM in individuals with asthma, after controlling for BMI. We also observed a higher prevalence and incidence risk of asthma in people with T2DM, suggesting that asthma and the T2DM relationship may be bidirectional. There are a number of potential underlying mechanisms for these observations.
This is the first systematic review of epidemiological studies on the interaction between these two conditions. Further work is required to investigate this relationship more, with clear index case definitions and control of potential confounding factors.

\section{CONSENT FOR PUBLICATION}

Not applicable.

\section{CONFLICT OF INTEREST}

AMcG has undertaken research funded by Eli Lilly and Company and AstraZeneca. SdeL has undertaken research funded by GlaxoSmithKline, AstraZeneca, Eli Lilly and Company, and Takeda.

The authors declare no conflict of interest, financial or otherwise.

\section{ACKNOWLEDGEMENTS}

Declared none.

\section{REFERENCES}

[1] Guibas GV, Mathioudakis AG, Tsoumani M, Tsabouri S. Relationship of Allergy with Asthma: There Are More Than the Allergy "Eggs" in the Asthma "Basket". Frontiers in pediatrics. 2017;5:92.

[2] Wenzel SE. Asthma: defining of the persistent adult phenotypes. Lancet. 2006;368(9537):804-13.

[3] Luder E, Ehrlich RI, Lou WYW, Melnick TA, Kattan M. Body mass index and the risk of asthma in adults. Respiratory Medicine 2004; 98(1):29-37

[4] Beuther DA, Sutherland ER. Overweight, obesity, and incident asthma: a meta-analysis of prospective epidemiologic studies. American journal of respiratory and critical care medicine. 2007;175(7):661-6.

[5] Schatz M, Zeiger RS, Yang SJ, Chen W, Sajjan S, Allen-Ramey F, et al. Prospective Study on the Relationship of Obesity to Asthma Impairment and Risk. The journal of allergy and clinical immunology. In practice. 2015;3(4):560-5 e1.

[6] Kankaanranta H, Kauppi P, Tuomisto LE, Ilmarinen P. Emerging Comorbidities in Adult Asthma: Risks, Clinical Associations, and Mechanisms. Mediators of inflammation. 2016;2016:3690628.

[7] Bell JA, Kivimki M, Hamer M. Metabolically healthy obesity and the risk of incident type 2 diabetes: a meta-analysis of prospective cohort studies. Obesity Reviews. 2014; 15(6): 504-515.

[8] Ford ES, Mannino DM. Prospective association between lung function and the incidence of diabetes: findings from the National Health and Nutrition Examination Survey Epidemiologic Followup Study. Diabetes Care. 2004;27(12):2966-70.

[9] Weir DC, Jennings PE, Hendy MS, Barnett AH, Burge PS. Transfer factor for carbon monoxide in patients with diabetes with and without microangiopathy. Thorax. 1988;43(9):725-6.

[10] Ehrlich SF, Quesenberry CP, Jr., Van Den Eeden SK, Shan J, Ferrara A. Patients diagnosed with diabetes are at increased risk for asthma, chronic obstructive pulmonary disease, pulmonary fibrosis and pneumonia but not lung cancer. Diabetes Care. 2010;33(1):5560.

[11] Liberati A, Altman DG, Tetzlaff J, Mulrow C, Gotzsche PC Ioannidis JP, et al.. The PRISMA statement for reporting systematic reviews and meta-analyses of studies that evaluate health care interventions: explanation and elaboration. Annals of internal medicine. 2009;151(4):W65-94.

[12] Stroup DF, Berlin JA, Morton SC, Olkin I, Williamson GD, Rennie $\mathrm{D}$, et al. . Meta-analysis of observational studies in epidemiology: a proposal for reporting. Meta-analysis Of Observational Studies in Epidemiology (MOOSE) group. JAMA. 2000;283(15):2008-12. 
[13] Booth A, Clarke M, Dooley G, Ghersi D, Moher D, Petticrew M, et al.. The nuts and bolts of PROSPERO: an international prospective register of systematic reviews. Systematic reviews. 2012;1:2.

[14] Rayner L, McGovern A, Creagh-Brown B, Woodmansey C, deLusignan

2017;Pageshttps://www.crd.york.ac.uk/prospero/display_record.asp $? \mathrm{ID}=\mathrm{CRD} 42017067421$

[15] Atkins D, Best D, Briss PA, Eccles M, Falck-Ytter Y, Flottorp S, et al.. Grading quality of evidence and strength of recommendations. BMJ. 2004;328(7454):1490.

[16] Schwarzer G. R meta-analysis: package 'meta'. 3.3 .2 ed; 2016.

[17] DerSimonian R, Laird N. Meta-analysis in clinical trials. Controlled clinical trials. 1986;7(3):177-88.

[18] Green JPHaS. A generic inverse variance approach to metaanalysis. Cochrane Handbook for Systematic Reviews of Interventions: Cochrane Collaboration; 2011.

[19] Tierney JF, Stewart LA, Ghersi D, Burdett S, Sydes MR. Practical methods for incorporating summary time-to-event data into metaanalysis. Trials. 2007;8:16.

[20] Higgins JP, Thompson SG, Deeks JJ, Altman DG. Measuring inconsistency in meta-analyses. BMJ. 2003;327(7414):557-60.

[21] Rana JS, Mittleman MA, Sheikh J, Hu FB, Manson JE, Colditz GA, et al.. Chronic obstructive pulmonary disease, asthma, and risk of type 2 diabetes in women. Diabetes Care. 2004;27(10):2478-84.

[22] Song Y, Klevak A, Manson JE, Buring JE, Liu S. Asthma, chronic obstructive pulmonary disease, and type 2 diabetes in the Women's Health Study. Diabetes research and clinical practice. 2010;90(3):365-71.

[23] Yun HD, Knoebel E, Fenta Y, Gabriel SE, Leibson CL, Loftus EV, Jr., et al. . Asthma and proinflammatory conditions: a populationbased retrospective matched cohort study. Mayo Clinic Proceedings. 2012;87(10):953-60.

[24] Mueller NT, Koh WP, Odegaard AO, Gross MD, Yuan JM, Pereira MA. Asthma and the risk of type 2 diabetes in the Singapore Chinese Health Study. Diabetes research and clinical practice. 2013;99(2):192-9.

[25] Sterne JA, Sutton AJ, Ioannidis JP, Terrin N, Jones DR, Lau J, et al.. Recommendations for examining and interpreting funnel plot asymmetry in meta-analyses of randomized controlled trials. BMJ. 2011;343:d4002.

[26] Hashemzadeh M, Movahed MR. The occurrence of asthma in hospitalized patients with type 2 diabetes mellitus. Internal medicine journal. 2009;39(10):699-701.

[27] Thomsen SF, Duffy DL, Kyvik KO, Skytthe A, Backer V. Risk of asthma in adult twins with type 2 diabetes and increased body mass index. Allergy. 2011;66(4):562-8.

[28] Chen CZ, Hsu CH, Li CY, Hsiue TR. Insulin use increases the risk of asthma but metformin use reduces the risk in patients with diabetes in a Taiwanese population cohort. The Journal of asthma: official journal of the Association for the Care of Asthma. 2017:0.

[29] Liu S, Tinker L, Song Y, Rifai N, Bonds DE, Cook NR, et al.. A prospective study of inflammatory cytokines and diabetes mellitus in a multiethnic cohort of postmenopausal women. Archives of internal medicine. 2007;167(15):1676-85.

[30] Shore SA. Obesity and asthma: possible mechanisms. The Journal of allergy and clinical immunology. 2008;121(5):1087-93; quiz 945.

[31] Ahmad T, Kumar M, Mabalirajan U, Pattnaik B, Aggarwal S, Singh R, et al.. Hypoxia response in asthma: differential modulation on inflammation and epithelial injury. American journal of respiratory cell and molecular biology. 2012;47(1):1-10.

[32] Kim SY, Yoo CG, Lee CT, Chung HS, Kim YW, Han SK, et al. Incidence and risk factors of steroid-induced diabetes in patients with respiratory disease. Journal of Korean medical science. 2011;26(2):264-7.

[33] Egbuonu F, Antonio FA, Edavalath M. Effect of inhaled corticosteroids on glycemic status. The open respiratory medicine journal. 2014;8:101-5.

[34] Pitocco D, Fuso L, Conte EG, Zaccardi F, Condoluci C, Scavone $\mathrm{G}$, et al.. The diabetic lung--a new target organ? The review of diabetic studies : RDS. 2012;9(1):23-35

[35] Sandler M, Bunn AE, Stewart RI. Cross-section study of pulmonary function in patients with insulin-dependent diabetes mellitus. The American review of respiratory disease. 1987;135(1):223-9.

[36] van den Borst B, Gosker HR, Zeegers MP, Schols AM. Pulmonary function in diabetes: a metaanalysis. Chest. 2010;138(2):393-406.

[37] Brashier B, Salvi S. Obesity and asthma: physiological perspective. Journal of allergy. 2013;2013:198068.

[38] Savage-Brown A, Mannino DM, Redd SC. Lung disease and asthma severity in adults with asthma: data from the Third National Health and Nutrition Examination. The Journal of asthma : official journal of the Association for the Care of Asthma. 2005;42(6):51923

[39] Bottini P, Scionti L, Santeusanio F, Casucci G, Tantucci C. Impairment of the respiratory system in diabetic autonomic neuropathy. Diabetes, nutrition \& metabolism. 2000;13(3):165-72.

[40] Li Y, Saito M, Tobimatsu S, Oshida H, Hori Y, Fuchigami H, et al.. Prediabetes and impaired lung function in asymptomatic adults. Diabetes research and clinical practice. 2013;100(2):e51-4.

[41] Singh S, Prakash YS, Linneberg A, Agrawal A. Insulin and the lung: connecting asthma and metabolic syndrome. Journal of allergy. 2013;2013:627384.

[42] Singh S, Bodas M, Bhatraju NK, Pattnaik B, Gheware A, Parameswaran PK, et al.. Hyperinsulinemia adversely affects lung structure and function. American journal of physiology. Lung cellular and molecular physiology. 2016;310(9):L837-45.

[43] Zhou G, Myers R, Li Y, Chen Y, Shen X, Fenyk-Melody J, et al. Role of AMP-activated protein kinase in mechanism of metformin action. The Journal of clinical investigation. 2001;108(8):1167-74.

[44] Lee JS, Park SJ, Cho YS, Huh JW, Oh YM, Lee SD. Role of AMPActivated Protein Kinase (AMPK) in Smoking-Induced Lung Inflammation and Emphysema. Tuberculosis and respiratory diseases. 2015;78(1):8-17.

[45] Stene LC and Nafstad P. Relation between occurrence of type 1 diabetes and asthma. Lancet. 2001; 357 (9256): 607-8.

[46] Maddatu J, Anderson-Bacum E and Evans-Molina C. Smoking and the risk of type 2 diabetes. Translational Research. 2017; 184: 101107

[47] Tuomilehto J, Lindstrom J, Eriksson JG, Valle TT, Hamalainen H et al.. Prevention of Type 2 Diabetes Mellitus by changes in lifestyle amongst subjects with impaired glucose tolerance. New England Journal of Medicine. 2001; 344: 1343-1350.

[48] Diabetes Australia. Prevention. Available at: https://www.diabetesaustralia.com.au/prevention. [Accessed $8 / 4 / 18]$

[49] Beasley R, Semprini A and Mitchell EA. Risk factors for asthma: is prevention possible? Lancet. 2015; 386(9998): 1075-1085.

DISCLAIMER: The above article has been published in Epub (ahead of print) on the basis of the materials provided by the author. The Editorial Department reserves the right to make minor modifications for further improvement of the manuscript. 